\title{
DELINQUÊNCIA JUVENIL FEMININA: UM FENÔMENO SOCIAL ${ }^{1}$
}

\author{
FEMALE JUVENILE DELINQUENCY: A SOCIAL PHENOMENON
}

\author{
Débora Wegner Maus², Lílian Soares Christofari², Maria Eduarda Bortoluzzi Diaz², \\ Bárbara Gonçalves D’ávila², Fernanda Pires Jaeger ${ }^{3}$ e Janaína Pereira Pretto Carlesso ${ }^{3}$
}

\section{RESUMO}

Nas últimas décadas o fenômeno da delinquência juvenil feminina aumentou significativamente em diversos países. O presente artigo teve por objetivo compreender os fatores e significados sociais que adquirem influência perante a delinquência juvenil feminina. Dessa forma, foi realizada uma pesquisa bibliográfica com abordagem metodológica qualitativa durante o segundo semestre do ano de 2020. Sendo utilizadas as seguintes bases de dados eletrônicas: Google Acadêmico, PepSic, Scielo e Bireme (BVS), e selecionados artigos científicos, livros e teses nacionais e internacionais que tratam sobre o tema. Assim, inferiu-se que há vários fatores que podem criar condições para que jovens meninas comecem a cometer crimes. Esses fatores incluem aspectos socioeconômicos e culturais, assim como relacionados a relações familiares negligentes, históricos de esquecimento e abandono escolar e influência de grupos de pares, contextos esses que assumem diversos sentidos na significação do crime e dos comportamentos desviantes na vida das jovens. Logo, considerando também que as jovens ainda se encontram invisibilizadas pelo o que é construído pelo masculino no fenômeno da delinquência juvenil, os resultados apresentados nesse estudo permitiram inferir que as nuances da delinquência juvenil feminina precisam ser analisadas de forma a compreender que existem características subjetivas que formam e conformam jovens mulheres à entrada no crime.

Palavras-chave: comportamentos delinquentes, meninas, significados sociais, fatores sociais, invisibilidades.

\section{ABSTRACT}

In the last decades, the phenomenon of female juvenile delinquency has increased significantly in several countries. This article aimed to understand the meanings and social factors that influence female juvenile delinquency. We carried out a bibliographic review with a qualitative methodological approach during the second semester of 2020. The following electronic databases were used: Google Scholar, PepSic, Scielo and Bireme (BVS), and selected national and international scientific articles, books and theses that deal with the theme. We found several factors that create conditions for female juvenile to begin committing crimes. These factors include socioeconomic and cultural aspects, as well as related to negligent family relationships, history of forgetfulness and school dropout and influence of peer groups, contexts that assume different meanings of crime and deviant behavior in the lives of young women. Considering also that young women are still invisible by what is built by men in the phenomenon of juvenile delinquency, the results presented in this study allowed us to infer that the nuances of female juvenile delinquency need to be analyzed in order to understand that there are subjective characteristics that conform and shape young women to enter crime.

Keywords: delinquent behaviors, girls, social meanings, social factors, invisibilities.

1 Artigo produzido nas disciplinas de Psicologia da Adolescência e de Escrita Científica e Pesquisa em Psicologia I, no Curso de Graduação em Psicologia da Universidade Franciscana - UFN.

2 Acadêmicas do Curso de Graduação em Psicologia da Universidade Franciscana - UFN. E-mails: d.maus@ufn.edu.br; lilian.soares@ufn.edu.br; m.diaz@ufn.edu.br; barbara.davila@ufn.edu.br

3 Docente do Curso de Graduação em Psicologia da Universidade Franciscana - UFN. E-mails: fpjaeger@ufn.edu.br; janaina.carlesso@ufn.edu.br 


\section{INTRODUÇÃO}

O fenômeno que compreende a delinquência juvenil entre meninas vem aumentando em muitos países do mundo desde as últimas décadas (ASSIS; CONSTANTINO, 2001). No Brasil, segundo Varella (2017), o avanço veio se dando a partir do crescimento dos centros urbanos e do desenvolvimento econômico que modificou a estrutura familiar tradicional e oportunizou as mulheres questionar o modelo patriarcal da sociedade e conquistar direitos e benefícios até então muito distantes. Mas essa conquista, no entanto, não se deu de forma homogênea em todas as camadas sociais, a violência nas periferias das cidades acentuou a desigualdade de gênero e expôs as jovens a questões como a gravidez na adolescência e criação dos filhos por conta própria, desestruturação familiar e muitas vezes a ausência da figura paterna, estupros, uso de drogas ilícitas e convivência com parceiros violentos (VARELLA, 2017).

Tendo em vista que o Estatuto da Criança e do Adolescente (ECA) prevê a execução de medidas socioeducativas para adolescentes que apresentam comportamentos desviantes e de oposição às leis (BRASIL, 1990), segundo dados da Pesquisa Nacional de Medidas Socioeducativas em Meio Aberto levantados pelo Ministério da Cidadania, no ano de 2018 havia 117.207 adolescentes em cumprimento de medidas socioeducativas de liberdade assistida e/ou prestação de serviços à comunidade, dentre os quais 13.104 eram meninas (BRASIL, 2018). Além disso, dentre os 22 mil jovens internados nas 461 unidades socioeducativas em funcionamento no país, 841 eram meninas (ANDRADE; FARIELLO, 2018). Pode-se inferir, no entanto, que o número de jovens meninas em vulnerabilidade social, expostas a violências e inseridas no meio do crime como praticantes de atos infracionais é ainda maior.

Apesar de serem minoria quando comparado o gênero, em um cenário de precariedade socioeconômica e cultural, onde há a constante violação de direitos básicos e a exposição a vivências de adversidades, o processo de desenvolvimento humano individual e de subjetivação dessas meninas são de certa forma afetados (OLIVEIRA et al., 2018). Os comportamentos de jovens delinquentes são inconsistentes com os estereótipos de comportamentos femininos adotados e tradicionalmente aceitos pela sociedade, o que faz com que os delitos por elas cometidos sejam vistos não como formas de se expressarem ativamente dentro do seu contexto sociocultural e contra o sistema que rege suas vidas, mas sim como formas de "masculinização" (DUARTE; CUNHA, 2014).

Esta visão traz a ideia de que as meninas agem de uma posição de fora daquilo que se constitui como feminilidade e partem para a posição do que é considerado masculino, pois quando se trata de meninos muitos comportamentos são considerados normais, tratados como características biológicas e intrínsecas ao sexo masculino, quais os indivíduos pertencentes ao sexo feminino estariam longe de adquirir tais atributos (DUARTE, 2011).

Dessa forma, é partindo da concepção de que os comportamentos dessas adolescentes constroem novas formas de experenciar e vivenciar diferentes feminilidades e que há nelas diferentes 
formas de significação e subjetivação diante de seus contextos sociais de negligencias, abusos e violências que este estudo se constitui. Sendo assim, o presente estudo partiu do seguinte questionamento: Quais são os fatores e significados sociais que adquirem influência perante a delinquência juvenil feminina?

A escolha da delinquência juvenil feminina como temática desse estudo surgiu pelo fato de muitas vezes as meninas delinquentes e suas histórias serem abafadas pelos meninos, justamente por esses serem a maioria quando se trata de delinquência juvenil. Dessa forma, o estudo pode contribuir para uma maior visibilidade dessas meninas, de seus contextos e suas reais necessidades, assim como para a desconstrução de conceitos referentes a feminilidade. Para a Psicologia, traz a possibilidade de novas propostas de pesquisas e estudos na área que enfatizem as questões que envolvam a relação entre as desigualdades sociais e a entrada dessas meninas sem oportunidades à delinquência e ao mundo criminal, como também para reflexões acerca de novas propostas de intervenções.

Portanto, o objetivo geral deste artigo é compreender os significados e sentidos que as meninas dão para os fatores que as levam a delinquência. Os objetivos específicos são identificar os fatores socioeconômicos e culturais, assim como examinar como as relações pessoais dentro da família, da escola e com os pares também adquirem influência na entrada ao crime e, por fim, relacionar esses fatores sociais com os significados que os mesmos assumem para as jovens meninas.

\section{METODOLOGIA}

A pesquisa apresentada se trata de uma pesquisa bibliográfica com abordagem metodológica qualitativa. Segundo Gil (2008), a pesquisa bibliográfica é caracterizada por ser desenvolvida com base em artigos científicos, livros, teses e dissertações já publicadas, onde abre para o pesquisador a possibilidade de compilar algumas informações e dados específicos sobre o assunto em pauta e assim realizar uma análise crítica e aprofundada. A pesquisa de caráter qualitativo visa analisar os fenômenos sociais por meio da análise de experiências de indivíduos e grupos dentro de um determinado contexto social, baseando-se na investigação de documentos já publicados (FLICK, 2009).

Tendo em vista os conceitos citados acima, a coleta de dados foi realizada no período de setembro a novembro de 2020. Os critérios para a seleção dos materiais utilizados foram artigos científicos, livros e teses nacionais e internacionais que comtemplam o tema da delinquência juvenil feminina. As bases de dados eletrônicas utilizadas para a pesquisa dos materiais foram: Google Acadêmico, PepSic, Scielo e Bireme (BVS). Ao final, foram escolhidos para a pesquisa 36 estudos e utilizados para a realização da pesquisa online, os seguintes descritores: delinquência juvenil, meninas, impacto social, significados sociais, fatores de risco.

Para realizar a análise dos dados coletados e selecionados, foram utilizadas as etapas da análise de conteúdo proposta por Bardin (2006). A análise de conteúdos se divide em três etapas, das quais a primeira, chamada pré-análise, permite realizar uma organização dos materiais com o intuito de 
selecionar através da leitura dos resumos, os materiais que realmente irão ser utilizados. A segunda etapa, chamada exploração do material, consiste na codificação e categorização do material através da descrição com base no referencial teórico e nas hipóteses do estudo. A terceira etapa, por fim, consiste na análise crítica dos dados selecionados e categorizados nas etapas anteriores e a inferência dos resultados.

\section{AMBIENTE SOCIOCULTURAL, INTERAÇÕES INTERPESSOAIS E SUAS INFLUÊN- CIAS NA CONSTRUÇÃO DO FENÔMENO}

A delinquência juvenil pode ser entendida como uma resposta a uma ordem social perversa que se sustenta através da imposição de padrões e da exclusão daquilo que não consegue os alcançar (CECCARELLI, 2001). Segundo Castro e Guareschi (2007), a exclusão além de ser econômica, através da pobreza e da vulnerabilidade constantes, ela é também um espelho para o sentimento de não pertencimento e para a ausência de respeito e reconhecimento.

De acordo com Pais (1996), a prevalência do delito juvenil está presente em maior parte nas populações mais vulneráveis e de nível socioeconômico mais enfraquecido. A desigualdade da estrutura social acentua a causa dos atos infracionais de jovens, já que "há uma crise econômico-social agravada, a cada dia, pela ausência de políticas sociais, combinadas com o descaso da sociedade civil e o descompromisso do mercado." (TELLES et al., 2006, p. 29). Assim sendo, jovens envolvidos em práticas antissociais são culpabilizados e privados de plena liberdade pelas condições de desigualdade econômica e social a qual estão submetidos (PATTO, 2017). Essa desigualdade gera a exclusão social do adolescente e sua família, caracterizada pelo desemprego, falta de acesso à educação, informação e saúde. E, como resultado, produz-se um conjunto de vulnerabilidades perpassadas por esses indivíduos, tendo no crime uma alternativa de fuga (FEIJÓ; ASSIS, 2004), e uma tentativa de inclusão dentro dos valores hegemônicos sociais (CASTRO; GUARESCHI, 2007).

Ainda, há o fato de que todos são bombardeados pelos meios de comunicação, com propagandas que igualam a posse de bens de consumo a uma validez de caráter pessoal, o que auxilia para a ocorrência de delitos dentre as populações mais vulneráveis (PATTO, 2017). A mídia assim toma papel de potencializadora de desigualdades e do consumismo exacerbado, que transmite para as meninas marginalizadas que o que está ao alcance delas é somente o desejo de possuir, e assim elas acabam reinventando formas que as possibilitem possuir. Dessa forma, pode-se inferir que "a violência pode ser pensada como uma forma de resistir às injustiças e ascender ao mundo do consumo" (CASTRO; GUARESCHI, 2007).

A adolescência por sua vez, é um período de descoberta de si mesmo, qual abre espaço para o indivíduo abandonar em partes a sua imagem infantil e projetar-se como um futuro adulto. Nesse contexto, acontecem mudanças físicas e hormonais, mudanças cognitivas e comportamentais, 
possibilitando o amadurecimento cerebral, mudanças no âmbito das relações sociais e mudanças emocionais (ABERASTURY; KNOBEL, 1981). Sabe-se ainda, que na adolescência comumente passa-se mais tempo com os pares em comparação com a família, devido a tentativa de descobrimento e afirmação da identidade. Porém, essa instituição não perde a importância, visto que as jovens internalizam os valores transmitidos pelos pais/familiares e, se construírem uma relação saudável, criam uma espécie de ambiente seguro e consolador que impulsiona o seu desenvolvimento (PAPALIA; FELDMAN, 2013). Mas, se a relação familiar é pautada em sentimentos como o de insegurança e de instabilidade, o desenvolvimento individual e subjetivo pode se dar de maneiras bem diferentes.

Segundo Hoyt e Scherer (1998), a estrutura familiar tem grande peso na formação dos indivíduos. Uma família patriarcal, onde a figura paterna e/ou masculina detém maior poder diante às relações familiares, é assumida para determinar os papéis que cada indivíduo deverá tomar dentro e fora do meio familiar. Essa estrutura traz uma perspectiva das diferenças nos níveis de significação da delinquência juvenil masculina e feminina, tendo em vista que os estereótipos assumidos para o gênero feminino são pautados na passividade e na obediência.

Dessa maneira, segundo Duarte (2011), um dos fatores que pode colocar em risco as adolescentes de desenvolverem comportamentos delinquentes e violentos se dá dentro de suas próprias famílias. Muitas meninas que entram para a criminalidade vivem em contextos de vulnerabilidade social, onde a família se encontra desestruturada e com dificuldades de manter boas relações com seus membros. Assim, elas vivenciam situações marcadas por punições severas e inconsistentes, negligências, maus-tratos e até mesmo abusos físicos e sexuais, o que acaba por suscitar o desenvolvimento de sentimentos e comportamentos hostis.

Ainda, a autora sustenta que há uma característica significativa quando se trata de adolescentes meninas, que faz com que a influência familiar tenha um papel ainda mais relevante do que para os meninos, pois as meninas veem com maior importância a qualidade dos relacionamentos, fazendo com que essa falta de reconhecimento, aceitação e respeito perante as relações familiares tenham um impacto maior na entrada à delinquência. Visto que, segundo Hoyt e Scherer (1998), problemas relacionados com a não aceitação dos pais e a repressão da identidade e da personalidade das jovens meninas estão extremamente interligados com o desenvolvimento de comportamentos desviantes.

Sendo assim, com um vínculo familiar escasso e instável onde as práticas educativas parentais são de alguma forma falhas e abusivas, essas adolescentes ainda passam por não desenvolverem muitas habilidades cognitivas, o que contribui para o desinteresse e baixo rendimento escolar (GUIMARÃES et al., 2018). No contexto escolar, portanto, essas meninas apresentam muitas vezes insucessos na aprendizagem, relações fracas com os professores e colegas e até mesmo são esquecidas e deixadas de lado pela instituição, fazendo com que se sintam deslocadas naquele meio, e dessa maneira, abre caminhos para que haja até mesmo abandono escolar (DUARTE, 2011). 
A relevância do contexto familiar e escolar em que as meninas estão inseridas é de grande importância na socialização das mesmas, visto que essas duas instituições são as primeiras onde o sujeito é posto diante ao meio social (GUIMARÂES et al., 2018). Segundo Matos (2006), a família e a escola são na realidade as instituições que primordialmente assumem um papel informal de reguladoras de comportamentos, especialmente comportamentos femininos que fogem dos estereótipos conhecidos e aceitos pela sociedade. Assim, ensinam modos de ser, viver e agir, punindo aqueles que se desviam das normas sociais vigentes e que não correspondem as expectativas de papéis pré-determinados.

Ainda, considerando o fato dito anteriormente, de a adolescência ser um período marcado por significativas mudanças no desenvolvimento psicossocial do indivíduo e pela busca de identidade e autonomia, normalmente os adolescentes no geral tendem a buscar novos ambientes de relacionamentos fora da família e da escola (MARCELLI; BRACONNIER, 2007).

Sendo assim, as suas relações com os pares são de extrema influência para as jovens meninas, visto que diversas vezes elas acabam por se envolver com amigos e parceiros sexuais e/ou românticos que as levam a um aumento dos comportamentos delinquentes através da pressão sofrida diante dos mesmos, levando por exemplo, a aquisição de hábitos como o consumo exacerbado de álcool e drogas (DUARTE, 2011). Dessa forma, tendo em vista que a juventude é uma fase que considera a aprovação do grupo, essas jovens também cometem infrações pela influência dos amigos. Entretanto, estes nem sempre têm a intenção de prejudicá-las, somente tomam estas atitudes porque corresponde à realidade que lhes é apresentada, já que também estão inseridos nesse ambiente onde experenciam a violência e a exclusão.

Porém, nem toda relação entre os pares é considerada um fator de risco à delinquência. Em um estudo realizado por Hu et al. (2020), observou-se que a qualidade da relação com os pares no período do ensino médio vivenciada por meninas adolescentes, pode tanto ser um fator de risco para a delinquência se há o envolvimento com pares que apresentam comportamentos desviantes e antissociais, quanto um fator protetivo se a relação é positiva, baseada em aceitação, respeito, apoio e suporte emocional.

Mas ainda, segundo Cauffman et al. (2008), os níveis mais altos de influência dos parceiros românticos e/ou sexuais em comportamentos desviantes e delinquentes para as meninas foram associados a baixos níveis de atenção e preocupação paterna, assim como níveis mais altos de hostilidade paterna, ou até mesmo a falta da figura paterna. Abrindo espaço para constatar que se não há para essas jovens um ambiente acolhedor e de escuta atenciosa para que se sintam confortáveis em questionar e expor suas angústias dentro de suas próprias famílias, há a procura por essa falta fora dela, ficando suscetíveis a qualquer tipo de influências.

Assim, infere-se que a delinquência juvenil feminina é influenciada em sua maioria por uma sucessão de eventos estressores apresentados a essas meninas desde seu nascimento. O trauma do abuso sexual, a violência física, o envolvimento com as drogas e outros contextos prejudiciais que desenvolvem sentimentos de angústia, ansiedade e comportamentos agressivos, motivam essas jovens a 
entrar para o mundo da criminalidade, se associando a grupos que constroem seus próprios princípios e valores e praticam a brutalidade social (DUARTE; CUNHA, 2014). Dessa maneira, pode-se considerar também, que muitas meninas acabam deixando a escola e/ou fugindo de casa, o que abre oportunidade para, por exemplo, o maior envolvimento com pares delinquentes, para a práticas de furtos, início precoce da vida sexual, assim como a gravidez na adolescência, a prostituição e até mesmo o envolvimento com gangues criminais e tráfico de drogas (DELL'AGLIO et al., 2005).

Vale ressaltar ainda, que a grande diferença entre meninos e meninas e seus comportamentos desviantes está na forma com que os mesmos reagem a esses eventos estressores que adquirem fator determinante à entrada no crime. E as maneiras com que os sujeitos dos diferentes sexos reagem dizem muito sobre a concepção do que se constitui como sendo masculinidade e feminilidade, pois os eventos estressores vivenciados em ambientes de desestruturação familiar, agressões físicas, sexuais e psicológicas, são significados e experenciados de maneiras diferentes. Segundo Schwartz e Clemons (2014), os meninos são mais propensos a externalizar seu estresse em outras pessoas. Já as meninas muitas vezes acabam por internalizar esse estresse justamente pela cultura impor as mulheres submissão, paciência, tolerância e simpatia constantemente reforçados dentro dos grupos sociais que se encontram inseridas desde seu nascimento, como a família, a escola e os grupos de pares, retratados nessa seção.

\section{SIGNOS DAS FEMINILIDADES}

Muito do que se entende por delinquência juvenil se deriva de dados estatísticos sobre os comportamentos masculinos, o que normalmente acaba sustentando também explicações para as experiencias femininas (SCHAFFNER, 1998). Porém, considerando que existem construções socialmente aceitas sobre aquilo que é considerado como sendo gêneros e que essas construções possuem grande influência na forma como cada sujeito se forma em sua subjetividade e como vem a se comportar no meio social, é inviável pensar a delinquência juvenil feminina com um olhar partindo do que é constituído e construído pelo masculino.

A participação da figura feminina na delinquência é caracterizada por suas histórias de invisibilidades retratadas no senso comum, em discursos de caráter político e inclusive nas estatísticas e estudos científicos em diversos países (DUARTE; CARVALHO, 2013). De acordo com Duarte (2011), o que exemplifica alguns aspectos dessas invisibilidades, é o fato de que as meninas têm estado ausentes na história cultural da adolescência, pois ao contrário dos meninos, elas são incentivadas a verem seu futuro de uma perspectiva patriarcal, onde devem almejar serem boas filhas, mães e esposas. Dessa forma, a juventude vivenciada pelas mulheres acaba se dando em uma transição de uma esfera familiar para outra, onde não há espaço para o desenvolvimento identitário satisfatório e característico do período da adolescência. 
Inclusive, a construção social patriarcal do que significa ser mulher, ensina as jovens meninas que a sensualidade física e o romance podem substituir a intimidade, a cultura emocional e o respeito mútuo, impondo a falsa crença de que elas necessitam de algo ou alguém que as proporcione subsídios para se constituírem em suas singularidades. Assim, acabam por desde cedo internalizar noções de uma solução sexual e romântica para as suas necessidades emocionais, familiares, educacionais e até mesmo de desenvolvimento (MATOS, 2006). Essa sequência neurótica massacra a vida das mulheres que se veem elas próprias sem entender quais são suas reais necessidades e desejos.

Nessa perspectiva, há a elaboração de estereótipos e preconceitos que trazem consigo imagens e representações "que sugerem a biologização, a sexualização, a patologização e a masculinização dos comportamentos femininos" (DUARTE; CARVALHO, 2013). A mídia, por sua vez, contém papel importante quando é pensado a sexualização da figura feminina e o reforçamento de estereótipos que são alavancados por uma sociedade consumista (CHESNEY-LIND; ELIASON, 2006). A imagem do feminino ideal traz em seu contraste a imagem do feminino repudiado. É através da imagem do feminino repudiado que adentrou na sociedade os estereótipos das "meninas rebeldes" e "meninas más", que dizem muito sobre como a delinquência feminina é vista ainda como um fenômeno pouco importante e que não constitui problema social (CHESNEY-LIND; ELIASON, 2006; DUARTE; CARVALHO, 2013).

Segundo Abrams et al. (2000), a construção social da representação das chamadas "meninas rebeldes" se deu a partir do início do século XX, quando as mulheres de classe média/alta começaram a adentrar as universidades e as de classe trabalhadora iniciaram um movimento para os grandes centros urbanos a fim de conseguirem trabalhos remunerados. Junto a isso, surgiu também a concepção de adolescência, antes não reconhecida como um período de transição da infância para a idade adulta (ARIÈS, 1981). Dessa forma, houve a tentativa de proteger as meninas das tentações dos centros urbanos e controlar seus impulsos vindos dessa nova forma de ver-se e fazer as feminilidades. Essa tentativa se deu através dos centros de reabilitações, que tinham como objetivo transformar essas meninas na imagem patriarcal ideal de mulher (ABRAMS et al., 2000).

Essa maneira de lidar com as meninas delinquentes aderida pelos centros socioeducativos, atualmente se traduz em medidas baseadas no modelo masculino que desconsidera suas diferentes formas de encarar e significar os fatores que as levaram a cometer crimes e a infringir a lei (OLIVEIRA et al., 2018). De acordo com Chesney-Lind e Eliason (2006), está implícita na teoria contemporânea da masculinização da violência feminina a noção de que as mesmas não precisam atender ao gênero, e sim somente assumir que os mesmos motivos que levam os meninos a cometerem atos violentos levam as meninas também, pois estas estão cada vez mais se libertando das restrições impostas pelo seu gênero, restrições baseadas em uma feminilidade controlada, uma feminilidade passiva. Porém, essa é uma visão incompleta e parcialmente errônea sobre o fenômeno, que abre brecha para um julgamento simplista e severo das meninas marginalizadas que apresentam qualquer desvio do comportamento feminino tradicional esperado. 
Tendo em vista que os tipos de atos mais cometidos por meninas no Brasil se caracterizam por não envolverem violência direta, como o tráfico de drogas, roubo e furto (BRASIL, 2018), as estatísticas que embasam o fenômeno da delinquência juvenil, segundo Schaffner (1998), refletem mitos socialmente aceitos sobre gênero e crime: meninos usam da violência, e meninas da sensualidade. Dessa forma, corrobora para o entendimento de que enquanto os meninos possuem uma maior tendência a se envolverem em crimes de violência direta, especialmente a violência física, as meninas frequentemente possuem formas menos diretas de agressões (SCHWARTZ; CLEMONS, 2014). O que Chesney-Lind e Eliason (2006) denominaram de "agressão relacional", onde as formas mais comuns de se expressarem é usando da violência verbal, como gritar, insultar, provocar e fazer intrigas. No entanto, os adolescentes, tanto meninos quanto meninas, estão mais propensos a cometerem crimes considerados de menor ofensas, como o abuso de álcool e drogas, pequenos furtos, fraudes e agressões simples, que podem incluir ameaças, agressões físicas como chutes, mordidas, arranhões, socos, empurrões e arremessos de objetos (SCHWARTZ; CLEMONS, 2014).

As motivações que impulsionam as meninas a entrar para a vida do crime na maioria das vezes se dão dentro da esfera das necessidades de sobrevivência e aceitação social, sejam elas traduzidas na grande responsabilidade que as meninas marginalizadas têm desde a infância com a tentativa de sobrevivência financeira dentro da própria família, que muitas vezes se encontra desestruturada e/ ou com constantes problemas relacionais entre seus membros, seja pela própria falta de oportunidades de se expressarem e serem reconhecidas pela sociedade que as cerca (VARELLA, 2017). Assim, os fatores que levam as meninas ao uso de drogas ilícitas, ao envolvimento com roubos e com o tráfico, acabam por exacerbar também estas discrepâncias na forma como são vivenciadas essas experiencias pelas meninas diferentemente dos meninos.

Um fator de diferenciação entre os gêneros na significação da entrada ao crime é o fato de que meninas engravidam. No Brasil, segundo Varella (2017), 21\% das parturientes do SUS são adolescentes com menos de vinte anos de idade, e esse é um fenômeno que compreende em sua maioria as camadas mais pobres e desfavorecidas da sociedade brasileira. Ainda segundo o autor, as adolescentes que na maioria das vezes se veem sozinhas para criar os filhos e/ou o parceiro acaba sendo morto, vítima da violência constante, muitas vezes veem no crime uma saída para seus problemas financeiros e esperança de um futuro com menor dificuldade. De acordo com Duarte (2011), diante a vulnerabilidade que se encontram as meninas delinquentes e os perigos que enfrentam nessa fase de desenvolvimento, a gravidez na adolescência e não planejada se traduz de uma negligência social para com essas meninas que carecem de informação adequada e não encontram oportunidades de poder enxergar e se aproximar de um futuro talvez idealizado.

Já quando entram para o crime, uma das diferenças que é de grande relevância para pensar o fenômeno, é o fato de que dentro das próprias organizações e grupos criminais as mulheres acabam por se localizar em lugares mais baixos da hierarquia de poder, principalmente as adolescentes 
(VARELLA, 2017). Dessa forma, elas acabam buscando outras formas de serem reconhecidas. Segundo um estudo realizado por Abramovay e Feffermann (2014), as meninas procuram o reconhecimento entre os meninos nas gangues, os quais ocupam os lugares mais altos dentro da hierarquia de poder formada no grupo. Como são impossibilitadas na maioria das vezes de chegar aos níveis mais altos da hierarquia, as meninas encontram outras formas de estarem mais no topo dessa estrutura de poder, como por exemplo, através da conquista dos líderes das gangues recorrendo a características típicas da feminilidade tradicional, como a sedução através do corpo, almejando a possibilidade de serem aceitas, respeitadas e possuírem maior autonomia dentro das gangues. As feminilidades construídas por jovens delinquentes, demonstram ser na realidade uma mistura daquilo que se considera tradicionalmente como sendo feminino juntamente com características envoltas por violências e estilos de vida que demandam uma maior autonomia, quebrando estereótipos, ainda que não consigam quebrar hierarquias.

Ainda, a forma de pensar a delinquência juvenil feminina como um fenômeno social traz consigo diferentes nuances que se deve considerar, como por exemplo a diferença racial. Segundo uma pesquisa realizada por Mendoza et al. (2019), as meninas no geral são menos propensas do que os meninos a serem encaminhadas para o sistema de justiça juvenil, porém quando comparado gênero e raça, as meninas negras são mais propensas a serem encaminhadas ao sistema de justiça juvenil do que as meninas brancas que cometem os mesmos delitos ou parecidos. E quando são encaminhadas, em outro estudo realizado por Bryson e Peck (2019), constatou-se que a cor de pele e o gênero influenciam também na decisão de dispensar os adolescentes de seus cumprimentos de medidas nos Estados Unidos, e os resultados mostraram que as meninas negras são mais propensas a serem desfavorecidas nesse quesito.

Por fim, considerando o que foi abordado nesta seção, Chesney-Lind e Eliason (2006) contemplam que a proposição de que há aumento significativo da violência entre meninas é na realidade uma reação contra o movimento feminista e antirracista, que possibilitaram a entrada das meninas e mulheres, especialmente pobres e negras, em espaços onde até então não eram aceitas e até mesmo hoje causam desconforto nas sociedades conservadoras e tradicionais. O fenômeno dessa forma, é visto majoritariamente como uma consequência da ansiedade cultural sobre a mudança das normas sociais em relação a gênero e raça (LUKE, 2008), assim como uma não aceitação das diferentes feminilidades ativas na sociedade que se traduzem em maiores números de adolescentes cumprindo medidas socioeducativas e um maior encarceramento de mulheres adultas que talvez fossem desnecessários em muitos casos (VARELLA, 2017).

\section{CONSIDERAÇÕES FINAIS}

A delinquência juvenil feminina traz à tona as invisibilidades que perpassam a vida de jovens meninas que se encontram desde muito cedo impossibilitadas de sequer sonhar com um futuro 
próspero e sem grandes dificuldades. É possível constatar que as jovens estão expostas a diversas situações que refletem seus comportamentos desviantes, os quais demonstram uma tentativa de fuga e de serem reconhecidas perante a sociedade, que parece esconder a dimensão desse problema atrás do cenário masculino que domina o fenômeno, e não se vê responsável sobre ele.

Visando o objetivo geral desse artigo de compreender os significados e sentidos que as meninas dão para os fatores que as levam a delinquência, os resultados apresentados nesse estudo permitiram inferir que as nuances da delinquência juvenil feminina precisam ser analisadas de forma a compreender que existem características subjetivas que formam e conformam jovens mulheres à entrada no crime. Dessa maneira, pode-se afirmar que a delinquência é desencadeada por inúmeros fatores, sejam eles econômicos, familiares, sociais ou psicológicos que acometem em sua maioria as populações que vivem em condições de precariedade e exclusão. A perspectiva das jovens mulheres, que tiveram sua infância negligenciada, muitas vezes responsável pela sobrevivência das suas famílias quando ainda adolescentes, com filhos, baixa escolaridade, histórico de violências doméstica e sexual, sem oportunidades de empregos etc., deve ser interpretada a partir de formas mais abrangentes e cuidadosas que permitam aplicar políticas públicas adequadas e em conformidade com as necessidades reais e básicas de toda mulher.

Em suma, esse estudo poderá contribuir para a desconstrução de estereótipos acerca das meninas infratoras que contribuem para o não reconhecimento do fenômeno em sua totalidade e afastam ainda mais as adolescentes em condições de vulnerabilidade da chance de poder construir diferentes histórias e percursos de vida. Ainda, durante a realização do estudo, verificou-se que são necessários mais pesquisas e estudos referentes a temática no país que possam contribuir para que haja significativas mudanças na forma de enxergar e agir sobre o fenômeno social. Dessa forma, considera-se que novos estudos na área da Psicologia, com enfoque especial na Psicologia Social, possam ser de grande valia para a compreensão da delinquência juvenil feminina e suas diferentes formas de ser e se fazer presente na sociedade contemporânea.

\section{REFERÊNCIAS}

ABERASTURY, A; KNOBEL, M. Adolescência normal. Porto Alegre: Artes Médicas, 1981.

ABRAMOVAY, M.; FEFFERMANN, M. Novas feminilidades e gangues em Brasília. In: DUARTE, V. M. S; CUNHA, M. I. (Orgs). Violências e Delinquências Juvenis Femininas: Gênero e (In)visibilidades Sociais. Húmus, 2014. Disponivel em: https://bit.ly/3AlrAhu. Acesso em: 22 set. 2020

ABRAMS, L. S; CURRAN, L. Wayward Girls and Virtuous Women: Social Workers and Female Juvenile Delinquency in the Progressive Era. In: Affilia, v. 15, n. 1, p. 49-64. 2000. 
ANDRADE, P; FARIELLO, L. Há mais de 22 mil menores infratores internados no Brasil. Agência

CNJ de Notícias, Brasília, DF, nov. 2018. Disponível em: https://bit.ly/3hshdA0. Acesso em: 14 nov. 2020.

ARIÈS, P. História social da criança e da família. Rio de Janeiro: LTC, 2. ed, 1981.

ASSIS, S. CONSTANTINO, P. Filhas do mundo: infracção juvenil feminina no Rio de Janeiro. Rio de Janeiro: Editora FioCruz, 2001.

BARDIN, L. Análise de conteúdo. Lisboa: Edições 70, 2006.

BRASIL. Lei no 8.069/1990. Estatuto da Criança e do Adolescente. 1990. Disponível em: https:// bit.ly/3hwyV5w. Acesso em: 3 out. 2020.

BRASIL. Ministério da Cidadania. Secretaria Nacional de Assistência Social. Relatório da Pesquisa Nacional das Medidas Socioeducativas em Meio Aberto: no sistema único de assistência social. Brasília, DF, 2018.

BRYSON, S. L; PECK, J. H. Understanding the Subgroup Complexities of Transfer: The Impact of Juvenile Race and Gender on Waiver Decisions. In: Youth Violence and Juvenile Delinquency. p. 1-21. 2019.

CASTRO, A. L. S; GUARESCHI, P, A. Adolescentes autores de atos infracionais: Processos de exclusão e formas de subjetivação. In: Revista Psicologia Política. v. 7, n. 13. Porto Alegre, 2007.

CAUfFMAN, E. FARrugGiA, S. P. GOLDWEBER, A. Bad Boys or Poor Parents: Relations to Female Juvenile Delinquency. In: Jounal of Research on Adolescence. v. 18, n. 4, p. 699-712, 2008.

CECCARELLI, P. R. Delinqüência: resposta a um social patológico. In: Pulsional - Revista de Psicanálise. São Paulo: Livraria Pulsional, n. 145, 2001.

CHESNEY-LIND, M; ELIASON, M. From invisible to incorrible: The demonization of marginalized women and girls. In: CRIME MEDIA CULTURE. v. 2, n. 1, p. 29-47. 2006.

DELl'AGlio, D. D; BENETTI, S. P. C; DERETTI, L; D’INCAO, D. B; LEON, J. S. Eventos estressores no desenvolvimento de meninas cumprindo medidas sócio-educativas. In: Paidéia, v. 15, n. 30, p.119-129, 2005. 
DUARTE, V. M. S. Os caminhos de Alice do outro lado do espelho: Discursos e percursos na delinquência juvenil feminina. 2011. Tese de Doutoramento - Doutoramento em Sociologia - Especialidade de Sociologia e Metodologia Fundamentais, Universidade do Minho, Braga, 2011.

DUARTE, V. M. S; CARVALHO, M. J. L. (ENTRE) OLHARES SOBRE DELINQUÊNCIA NO FEMININO. In: ex aquo, n. 28, p. 31-44. Lisboa, 2013.

DUARTE, V. M. S; CUNHA, M. I. Violências e delinquências juvenis femininas: aproximações à questão. In: DUARTE, V. M. S; CUNHA, M. I. (Orgs). Violências e Delinquências Juvenis Femininas: Gênero e (In)visibilidades Sociais. Húmus, 2014. Disponivel em: https://bit.ly/3qFXz7M. Acesso em: 22 set. 2020

FEIJÓ, M. C; ASSIS, S. G. O Contexto de Exclusão Social e de Vulnerabilidades de Jovens Infratores e de suas Famílias. In: Estudos de Psicologia, v. 9, n. 1. p. 157-166. Campinas, 2004.

FLICK, U. Qualidade na pesquisa qualitativa: Coleção Pesquisa Qualitativa. Tradução: Roberto Cataldo Costa. 3. ed. Porto Alegre: Artmed, 2009.

GIL, A. C. Como elaborar projetos de pesquisa. 4. ed. São Paulo: Atlas, 2008.

GUIMARÃES, L. C; FRANCO, M. G. O; BAZON, M. R. Delinquência juvenil e maus-tratos: uma revisão crítica de literatura. In: Psicologia - Saberes \& Práticas, n. 2, v. 1, p. 28-37, 2018.

HOYT, S; SCHERER, D. G. Female Juvenile Delinquency: Misuderstood by the Juvenile Justice System, Neglected by Social Science. In: Law and Human Behavior. v. 22, n. 1. 1998.

HU, A; RYSIN, M. J. V. COLLINS, M. L. S. LEVE, L. D. Peer Ralations and Delinquency Among Girls in Foster Care Following a Skill-Building Preventive Intervention. In: Child Maltreatment. 2020.

LUKE, K. P. Are Girls Really Become More Violent? A Critical Analysis. In: Affilia: Journal of Women and Social Work. v. 23, n. 1, p. 38-50. 2008.

MARCELLI, D; BRACONNIER, A. Adolescência e psicopatologia [recurso eletrônico] / Daniel Marcelli, Alain Braconnier; tradução Fátima Murad. - 6. ed. - Dados eletrônicos. - Porto Alegre: Artmed, 2007. 
MATOS, R. M. N. C. Vidas raras de mulheres comuns: Percursos de vida, significações do crime e construção da identidade em jovens reclusas. 2006. Tese de Doutoramento em Psicologia - Área de Conhecimento em Psicologia da Justiça, Universidade do Minho, Braga, 2006.

MENDOZA, M; BLACKE, J. J; MARCHBANKS, M; RAGAN, K. Race, Gender and Disability and the Risk for Juvenile Justice Contact. In: The Journal of Special Education. Texas, 2019.

OLIVEIRA, M. C. S. L; COSTA, D. L. P; CAMARGO, C. K. Infração juvenil feminina e socioeducação: um enfoque cultural e de gênero. In: Estud. pesqui. psicol. v. 18, n. 1, p. 72-92. Rio de Janeiro, 2018.

PAIS, J. M. Levantamento bibliográfico de pesquisas sobre a juventude portuguesa: tradições e mudanças (1985-1995). In: Sociologia, Problemas e Práticas. n. 21, p. 121-197. Lisboa, 1996.

PAPALIA, D. E; FELDMAN, R. D. Desenvolvimento humano. 12. ed. Porto Alegre: AMGH, 2013. PATTO, M. H. S. Direitos Humanos e Desigualdade Social. In: IDE v. 39, n. 63, p. 185-197. São Paulo, 2017.

SCHWARTZ, J. CLEMONS, K. Identifying and understanding similarities and differences in adolescent girls' and boys' violent delinquencies. In: DUARTE, V. M. S; CUNHA, M. I. (Orgs). Violências e Delinquências Juvenis Femininas: Gênero e (In)visibilidades Sociais. Húmus, 2014. Disponivel em: https://bit.ly/3xaqy6c. Acesso em: 22 set. 2020

SHAFFNER, L. Female Juvenile Delinquency: Sexual Solutions, Gender Bias, and Juvenile Justice. In: Hastings Women's Law Journal. v. 9, n. 1, p. 1-25. 1998.

TELlES, T. S; CARLOS, V. Y; CÂMARA, C. B; BARROS, M. N. F; SUGUIHIRO, V. L. T. Criminalidade Juvenil: a vulnerabilidade dos adolescentes. In: Revista de Psicologia da UNESP. v. 5, n. 1, p. 29. Londrina, 2006.

VARELLA, D. Prisioneiras. São Paulo: Companhia das Letras, 2017. 